\title{
Switching to Work in an Inclusivity Workshop: Multimodal Analysis of Interaction
}

\author{
Rudneva E. A. \\ Institute for Linguistic Studies, \\ St. Petersburg, Russia \\ katja1985mt@yandex.ru
}

\begin{abstract}
The study focuses on switching from talk to work in an "inclusivity workshop" for people with mental disabilities. Work activities and conversation about general topics can be approached from the perspective of multiactivity and considered courses of actions intertwined in social interaction. The order of activities is negotiated among participants using both linguistic and non-linguistic means. The data are extracts of video recordings containing a participant getting others to do things. The paper provides multimodal analysis of 6 cases of an instructor getting an autistic participant to switch to work, which occurred within a 17-minute conversation about animals. In the data, the autistic participant never provides a second-pair response to a directive. In 5 out of 6 cases analysed in the paper he fulfils the action to different extents, demonstrating various degrees of involvement. Getting the autistic person to switch to work is more effective when suggesting actions one by one, through concrete embodied actions, and when orienting to phases of the ongoing talk. The study highlights differences between autistic and non-autistic participants switching from one course of actions to another. Considering goals of an inclusivity workshop, success of switching to work can be also determined by the opportunities for the smooth conversation.
\end{abstract}

Key words: multimodality; multimodal analysis; multiactivity; autism

DOI: $10.28995 / 2075-7182-2021-20-587-596$

\section{Переключение к рабочей деятельности в инклюзивной мастерской: мультимодальный анализ взаимодействия}

\author{
Руднева Е. А. \\ Институт лингвистических исследований РАН, \\ Санкт-Петербург, Россия \\ katja1985mt@yandex.ru
}

\begin{abstract}
Аннотация
Исследование посвящено переключению от разговора к работе в «инклюзивной мастерской для людей с особенностями развития психики и интеллекта». Рабочая активность и общение с коллегами на отвлеченные темы могут рассматриваться как виды деятельности, которые пересекаются в социальном взаимодействии. Согласование действий между собеседниками происходит при помощи языковых и неязыковых средств. Материал составили фрагменты видеозаписей, где происходит побуждение к действию. В статье анализируются 6 попыток инструктора подвигнуть сотрудника с аутизмом возобновить рабочую активность, которые совершаются в течение 17-минутного разговора о животных. В 5 из 6 случаев сотрудник выполняет действие в той или иной степени, переключаясь к работе скорее поэтапно и демонстрируя разный уровень включенности. Он ни разу не отвечает на побудительный речевой акт словами. Два курса деятельности соотносятся таким образом, что он говорит только о животных, при этом выполняет действия, связанные с работой. Эффективнее оказывается побуждение, которое сопровождается движениями, требующими ответных, к одному действию (а не к двум сразу); кроме того, важен ход разговора. Мультимодальный анализ выявляет различия в том, как происходит переключение между видами деятельности у аутичных и нейротипичных участников. На переключение к рабочей деятельности можно взглянуть с учетом задач инклюзивного пространства и посчитать успешным, если оно позволяет поддерживать текущую беседу.
\end{abstract}

Ключевые слова: мультимодальность; мультимодальный анализ; многозадачность; аутизм 


\section{1 Введение}

Инклюзивные мастерские представляют собой пространство, «где взрослые люди с особенностями развития психики и интеллекта работают и занимаются творчеством на равных с мастерами и волонтерами» ${ }^{1}$. Основная задача - создание условий для «осмысленного труда и общения». Часть сотрудников с ментальными особенностями официально трудоустроена и получает зарплату за работу в мастерских: столярной, швейной, графической, керамической. Присоединиться в качестве волонтера могут желающие, посетив установочную встречу. Кроме того, двери мастерских открыты для посетителей.

Я осуществляла включенное наблюдение, посещая мастерские в качестве волонтера в феврале марте 2020 г., и не скрывала своего исследовательского интереса, при необходимости, объясняя, что снимаю видео «для науки» ${ }^{2}$. Цель исследования - проанализировать, каким образом осуществляется взаимодействие на рабочем месте, с участием людей с ментальными особенностями. Статья посвящена одному из аспектов изучаемого взаимодействия - переключению между рабочей деятельностью и разговором.

\section{2 Согласование действий между собеседниками}

Рабочая активность и общение с коллегами на отвлеченные темы могут рассматриваться с точки зрения понятия мультиактивности (multiactivity), т.е. как виды деятельности, которые пересекаются в социальном взаимодействии различными способами [Haddington et al. 2014: 3]. Многозадачность на рабочем месте подразумевает согласование порядка действий между участниками. При этом возможны разные способы согласования и переключения к работе: в частности, с помощью движений телом или побудительных реплик [Kamunen, Haddington 2020].

Тому, как осуществляется побуждение в спонтанном взаимодействии, в особенности просьбам и ответным реакциях на них, посвящено множество работ в рамках прагматики и конверсационного анализа [см., напр., Drew, Couper-Kuhlen 2014, Ogiermann 2015, Rauniomaa, Keisanen 2012, Rossi 2015]. Пристальное изучение видео- и аудиозаписей позволяет расширять список реакций на побуждение, добавляя к стандартным (отказу, согласию, выполнению просьбы) другие, например, делегирование действия третьему лицу и ответное подшучивание [Rudneva 2019]. Отмечается, что на успешность просьбы влияет распределение внимания участников в момент ее совершения [Rauniomaa, Keisanen 2012]. При этом в работах по конверсационному анализу рассматриваются не только побудительные речевые акты, но шире - процесс вовлечения кого-то в деятельность (recruiting) - «использование широкого спектра семиотических средств для достижения цели с помощью другого участника» [Drew, Couper-Kuhlen 2014: 29].

В рамках теории вежливости П. Браун и С. Левинсона, побудительные речевые акты несут угрозу социальным лицам собеседников, которая смягчается при помощи стратегий лингвистической вежливости. Позитивная вежливость направлена на демонстрацию солидарности и общего между собеседниками, а негативная - на проявление уважения, уменьшение неудобства [Brown, Levinson 1987].

В центре внимания данной статьи находится переключение к рабочей деятельности сотрудника, у которого диагностирован аутизм. В следующем разделе вкратце представлены основные подходы к изучению взаимодействия с аутичными участниками.

\section{3 Основные подходы к изучению коммуникации с аутичными участниками}

Особенности коммуникации людей с аутизмом традиционно описываются в терминах нарушений - прежде всего, нарушений «модели психического» (theory of mind) [Baron-Cohen, Leslie, Frith 1985] и прагматических нарушений [Cummings 2012: 295]. Данный подход распространен в психологии [Медведовская, Лебедева 2011] и в области клинической прагматики [Cummings 2012].

\footnotetext{
${ }^{1}$ Информация с официального сайта организации «Простые вещи»: https://prostieveschi.ru/about-us.

${ }^{2}$ Все сотрудники при поступлении на работу подписывают согласие на видеосъемку. Кроме того, я каждый раз спрашивала у всех присутствующих разрешение на осуществление записи.
} 
Работы по конверсаиионному анализу ставят своей целью описать функции действий, напр., эхолалии (автоматических повторений) и формульных выражений, характерных для людей с аутизмом [Local, Wootton 1995; Dobbinson, Perkins, Boucher 2003]. Анализируется взаимодействие в институциональном контексте [Maynard, Turowetz 2020], а также внутри семьи (см. обзор в [Rae, Ramey 2020: 66-69]). К анализу семейного общения применяется, кроме того, лингвоантропологический подход [Ochs et al. 2004].

Сложности коммуникации аутичных и неаутичных участников могут рассматриваться как интеракционная проблема [Milton 2012: 884]. В рамках подхода «обоюдной эмпатии» Д. Милтона, непонимание - не результат нарушений человека с аутизмом, а общая проблема участников [Milton 2012, Williams 2020].

Настоящее исследование опирается на последние три подхода, а именно в нем 1) применяется методология конверсационного анализа; 2) анализируется взаимодействие, за которым велось длительное включенное наблюдение и в максимальной степени учитывается контекст; 3) понимание рассматривается как достижение всех участников, демонстрируются различия в точках зрения коммуникантов, при этом ни одна из них (ни аутичная, ни нейротипичная) не считается единственной нормой.

\section{4 Методология исследования}

Из видеозаписей, сделанных в инклюзивной мастерской (20 часов), были выбраны 20 фрагментов, где происходит побуждение к действию. В статье подробно анализируется один из эпизодов, записанный в керамической мастерской. На рабочем месте завязался разговор о содержании различных животных дома (17 минут), в течение которого инструктор совершает 6 попыток подвигнуть аутичного сотрудника возобновить рабочую деятельность. При помощи мультимодального анализа видеозаписи выясняется: 1) как организовано переключение к рабочей деятельности; 2) чем обусловлено достижение цели побуждения к возобновлению рабочей активности. В фокусе внимания оказываются побудительные действия инструктора, реакции аутичного сотрудника, роль побуждения в общем ходе взаимодействия.

Транскрипция видеозаписи выполнена по системе, разработанной лингвистом Л. Мондадой [Mondada 2018]. Мультимодальное транскрибирование представляет собой этап анализа данных и опирается на релевантность телесных действий для участников. В отличие от кодирования (когда используется конечное число заданных кодов для обозначения разных действий), при создании транскрипции есть возможность характеризовать движения с разной степенью детальности. По системе Л. Мондады, фиксируется соотношение речевых и телесных действий: для движения или жеста указывается точный момент начала и конца относительно речевой цепочки. Для каждого участника устанавливаются свои значки одновременности телесного действия с речевым, которыми обозначаются начало и конец (в речевой цепочке и под ней). Ниже представлены обозначения, используемые в настоящей статье ${ }^{3}$ :

$\Delta$ знак обозначает начало и конец телесного действия Марии

+ знак обозначает начало и конец телесного действия Василия

$\div$ знак обозначает начало и конец телесного действия Павла

>> действие началось до начала фрагмента

--> действие продолжается далее до момента, обозначенного аналогичным знаком и знаком

участника, напр.: -->

..... подготовка к действию

,,,, завершение действия

Речь участников выделяется жирным шрифтом, а инициал говорящего обозначается заглавной буквой, в то время как в случае телесных действий - строчной.

\footnotetext{
${ }^{3}$ В остальном транскрипция в настоящей статье следует принципам конверсационного анализа (список используемых обозначений представлен в приложении). Нумеруются все строки (в отличие от системы Л. Мондады), что удобнее при отсылке к транскрипции. Если неречевое действие следует за речевым, то неречевое действие называется и не обрамляется значками - это тоже удобнее для демонстрации разворачивания взаимодействия.
} 


\section{5 Анализ материала}

\section{Фрагмент 1}

В керамической мастерской завязался разговор о животных. Его участники: сотрудники с ментальными особенностями (Василий и Павел, у которого диагностирован аутизм), инструктор (называемый в сообществе «мастером») (Мария), волонтеры (Екатерина, Светлана). Отметим, что еще до начала диалога Павел прекратил лепку; он стоял и чистил фартук, беззвучно шевеля губами. Через 5 минут после начала разговора о животных Мария совершает первую, а затем вторую попытку подвигнуть Павла возобновить рабочую активность:

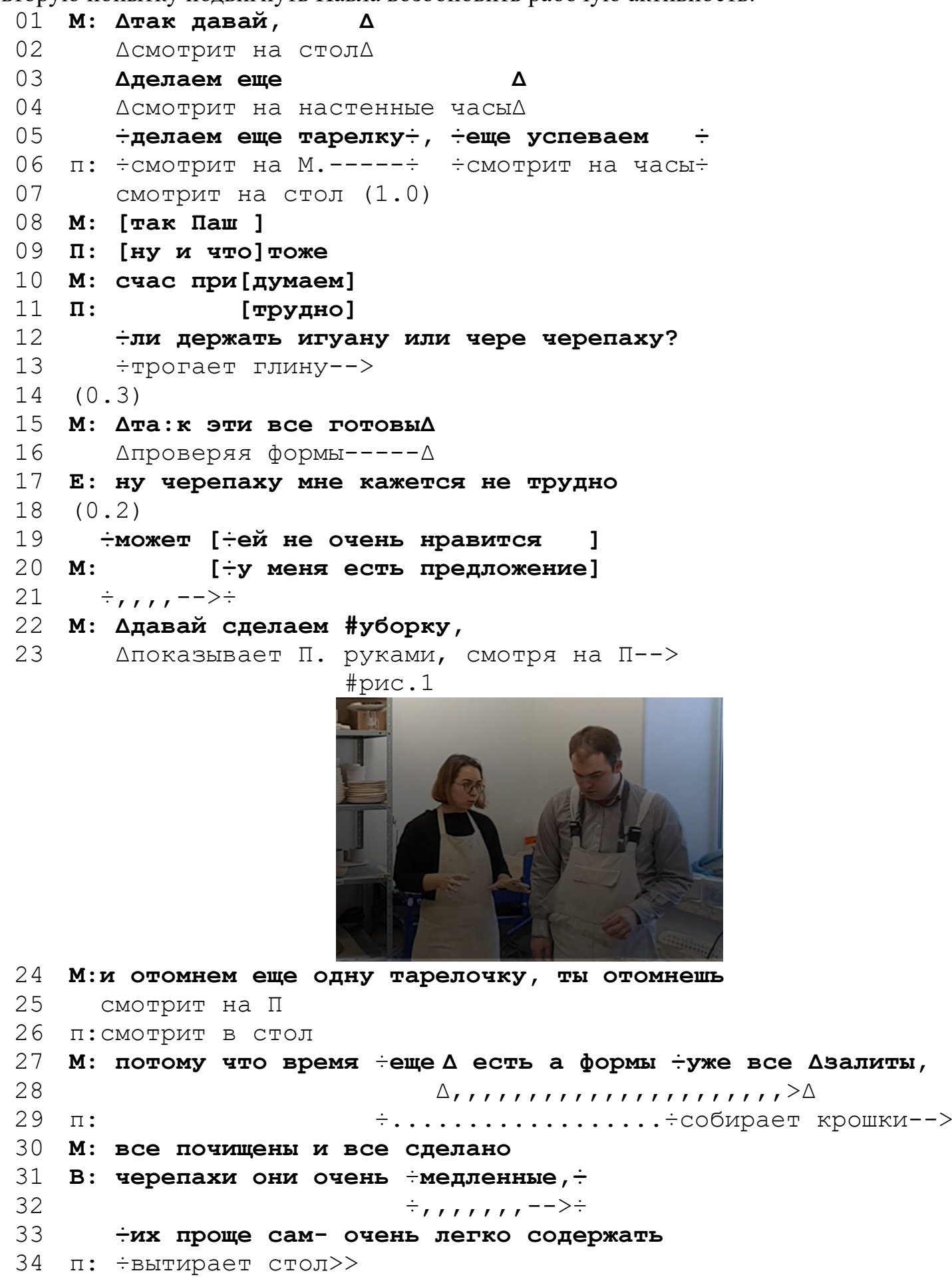


В анализируемом отрывке мастер по керамике Мария совершает попытки переключить Пашу к рабочей деятельности $(1-5,8-10,20-33)$. Она начинает делать это в возникшую паузу, когда, казалось бы, разговор о животных завершен. Сначала инструктор предлагает сделать «еще одну тарелочку», используя форму совместного действия (1 л. мн ч.) с частицей давай, при этом обращая внимание на время (сначала смотрит на настенные часы, потом отсылает фразой «еще успеваем») $(1,3,5)$. Обращение по имени и употребление формы совместного действия относятся, по Браун и Левинсону, к стратегиям позитивной вежливости, сближающей дистанцию между собеседниками. Далее следует аргументация $(27,30)$.

Павел, провожая взгляд Марии, также смотрит на часы, но, кроме этого, никак не реагирует на побуждение, продолжая разговор о животных. В данном фрагменте наблюдается некоторая несогласованность действий участников: Мария разговаривает о работе, а Павел совсем не переключается с беседы (8-12). Здесь наблюдается нетипичная ситуация, когда участники не реагируют на фразы друг друга: в частности, ожидается, что за побуждением последует ответное действие. Мастер, со своей стороны, игнорирует реплики о животных, даже вопрос (12), который представляет собой инициирующую реплику пары. Она пытается привлечь внимание сначала обращением (8), а затем телесными действиями (23, рис.1). Во втором случае Мария начинает фразу так, как будто совершает побудительное действие впервые: «У меня есть предложение» (20), и уже предлагает сначала заняться уборкой (22-23), а затем - тарелкой (24). Интересно, что в формулировке второго компонента этого «предложения», как его назвала Мария, содержится самопоправка: «и отомнем еще одну тарелочку, ты отомнешь» (24). После этого Павел начинает собирать крошки со стола.

Отметим, что в данном фрагменте происходит побуждение к двум действиям - лепке новой тарелки и уборке рабочего места (сперва именно в таком порядке). Во-первых, эти два действия могут различаться по степени необходимой включенности, в частности для Павла. Во-вторых, уборка отличается еще и тем, что нет четких границ между действиями, которые относятся и не относятся к ней: в частности, если человек собирает мелкие крошки со стола, то это уборка, но если он их кладет обратно, то нет.

В следующем фрагменте Мария 2 раза предлагает заняться уборкой:

\section{Фрагмент 2}

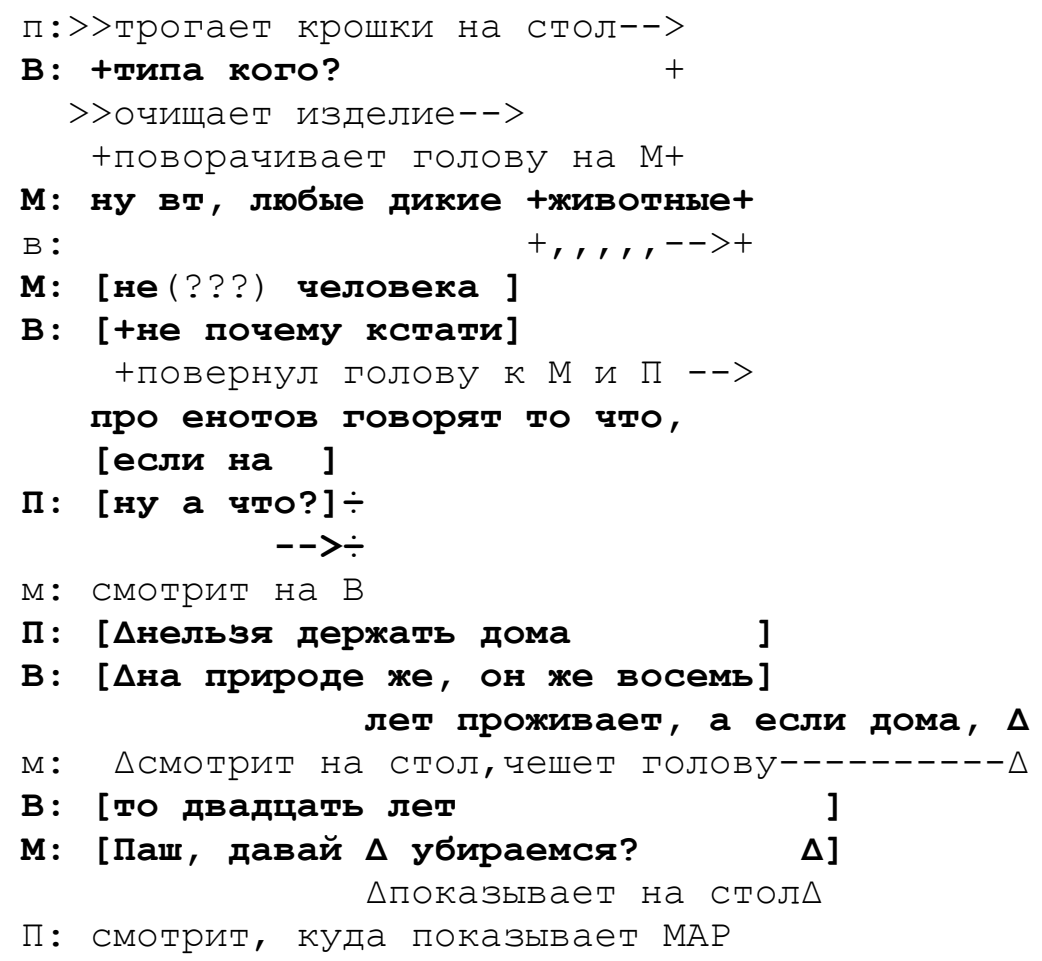


23 E: $\Delta \div$ но:+ вопрос еще, каких еще $\div$

24 м: \#рис. 2

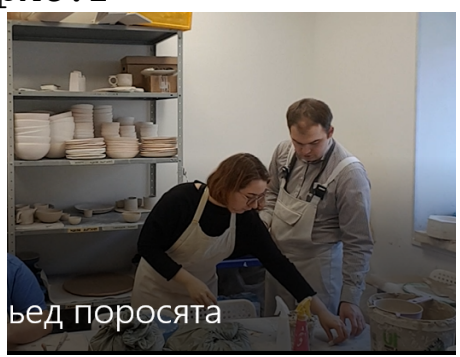

25 П: $\div$ протягивает руку к палочкам $\div$

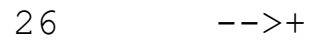

27 смотрит на E, улыбаясь

$28 \mathrm{E}:$ [ $\Delta$ *двадцать лет* ]

29 В: [Аи вообще, $\Delta$ двадцать лет]

$\begin{array}{lll}30 & \Pi: & \text { [ } \Delta \text { ище ещ, нельзя ли де]ржать дома (.) } \\ 31 & \text { м: } \triangle \text { дает палочки } \Pi \Delta\end{array}$

32 п: берет палочки и держит в руках

33 [ $\div$ Алемура или обезьяну? ]

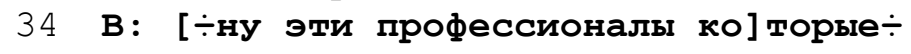

35 п: $\div$ перекладывает палочки в руках $\div$

36 м:

37 В: они те грят двадцать лет

38 [ $\Delta$ проживут дома]

39 М: [ $\Delta$ я думаю ],

40 п: $\quad \ldots \ldots \ldots . . . . .$. ставит палочки в стакан---, , , , , , , , $\Delta$

41 B: [нe ]

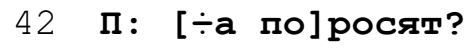

$\div$ смотрит на $\mathrm{M}-->$

в: смотрит на П

M: поросята они $\div$ домашние $\div$ особенно карликовые

$\Pi: \quad \div,,_{1},,^{-->\div}$

м: Ухмыляется

в : Ухмыляется

п: смотрит и улыбается

П : минипигиА

М:

$\triangle$ улыбается

$\triangle$ мотает головой $\triangle$

говорят они правда не очень добрые, нравом

убирает крошки

п: [стирает крошки с сита

м: [изображает злого поросенка]\#рис.3

\#рис. 3

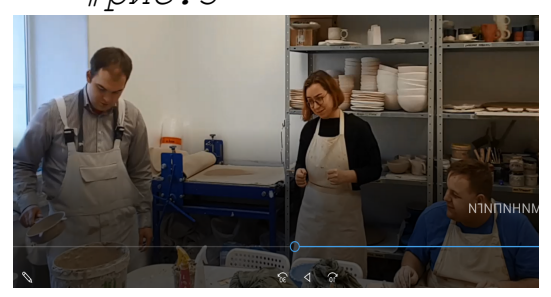

59

$\mathrm{E}: \div$ что вроде уже их на поводке

60 выгуливают в питере и москве -

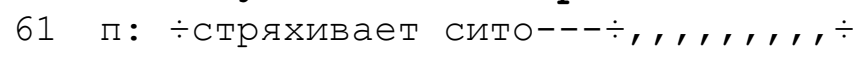




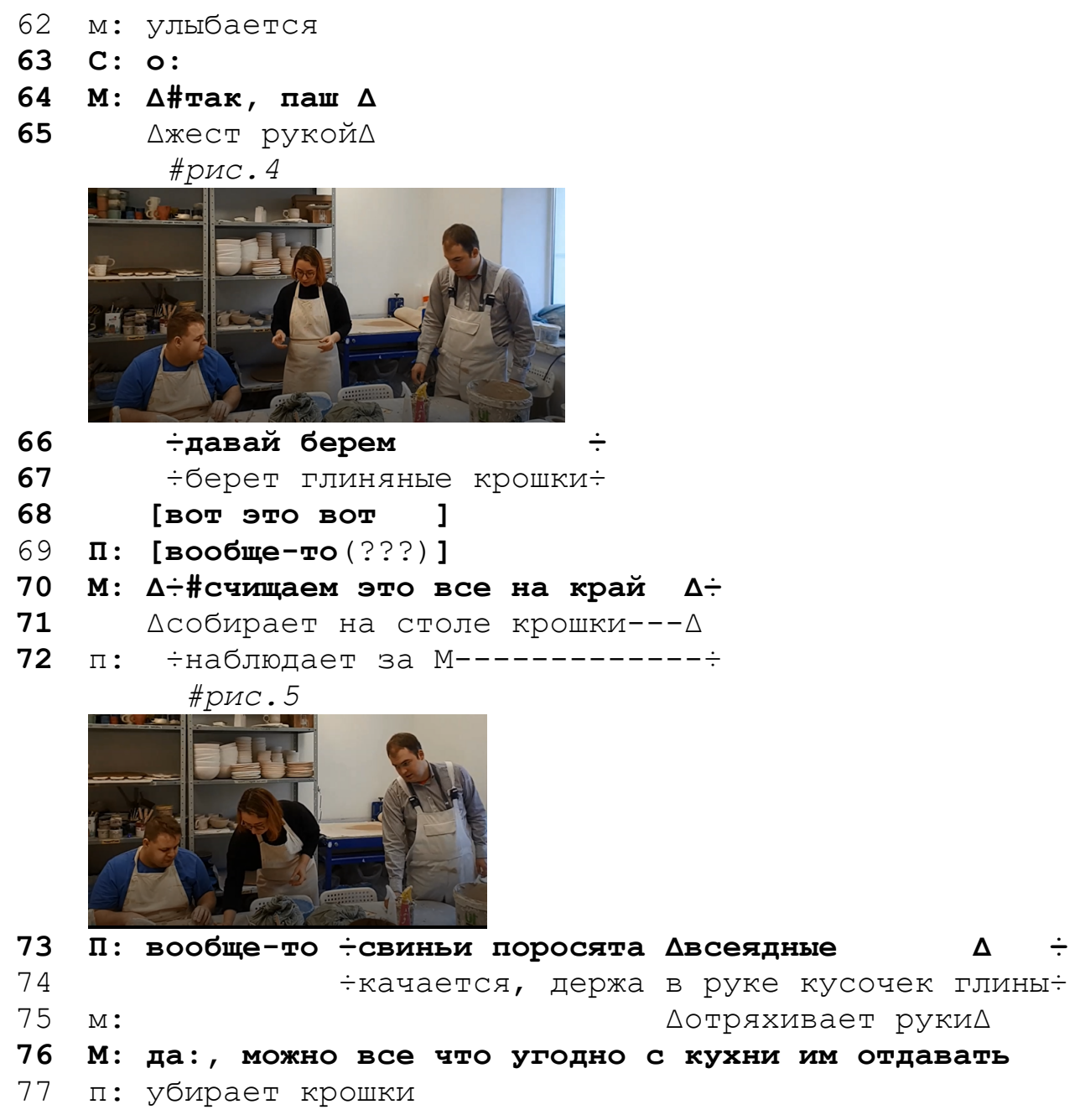

Здесь участники разбиваются на пары; анализ, представленный ниже, сосредотачивается на одной из них - Павла и Марии. Побудительная реплика снова оформляется как предложение с глагольной формой совместного действия (1 л. мн. ч.) и частицей давай (20) (позитивная вежливость, по Браун и Левинсону). Здесь происходит наложение реплик (19-20). После этого Мария наклоняется и собирает рукой палочки-стеки, Павел смотрит в направлении ее взгляда и наклоняется туда же (24-25). Мария, практически выхватывая палочки из рук Павла (рис. 2), собирает их и отдает ему. Павел таким образом возобновляет рабочую активность, но в пассивном формате, реагируя на телесные действия Марии (которые сложнее игнорировать, чем словесные). Параллельно с этими действиями, не требующими полного внимания, Павел продолжает разговор о животных, и формулировка вопроса повторяет структуру, которая использовалась им неоднократно ранее: «нельзя ли держать дома» (30). Затем он перекладывает палочки из рук в руки (35) - это действие находится на грани между рабочей деятельностью и нерабочей: совершаются манипуляции с предметами, но бесцельно, механически. Он ставит их в стакан (40), тем самым завершая этап уборки, который несколько растянулся. После этого, сначала переключившись на поросят/ «минипигов» (42 и далее), Павел самостоятельно переходит к следующему этапу уборки - вытирает крошки с сита (57) и стряхивает его (довольно резкими и громкими движениями) (61).

Следующее побудительное действие Марии (64-71) частично накладывается на начало еще одной реплики Павла о поросятах (68-69). Здесь мастер снова сопровождает инструкцию движениями тела и жестами, за которыми следит Павел $(65,67,71$, рис.5). Только завершив свою фразу (73), Павел приступает к уборке крошек (77). Отметим, что Мария и Павел практически не смотрят друг на друга, но в связи с данной совместной работой, это не является нарушением норм общения. 
Таким образом, здесь Павлу и Марии удается сочетать два курса деятельности, которые перемежаются мелкими фазами. Если сравнить этот фрагмент с первым, то разница прослеживается, прежде всего, в телесных действиях. В попытках, которые оказались успешными в том смысле, что за ними следуют необходимые действия, Мария активно использует движения телом, на которые сложнее не реагировать Паше. Кроме того, роль играет общий ход диалога. Так или иначе, получается, что Павел разговаривает только о животных, в то время как действия телом включают и рабочие.

Т.к. Павел продолжает уборку, но не переходит к изготовлению новой тарелки, Мария еще раз совершает побудительное речевое действие:

\section{Фрагмент 3}

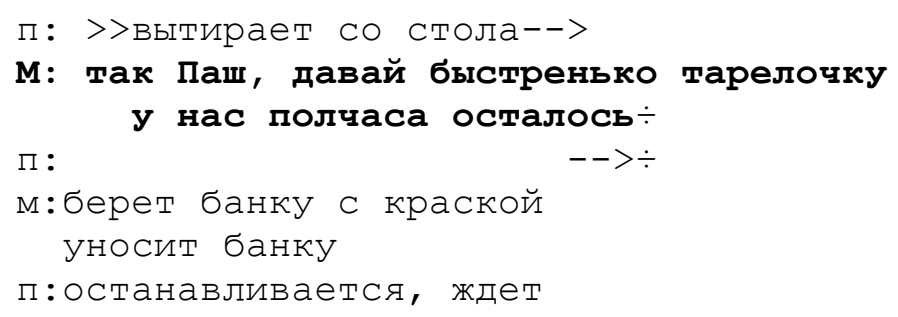

В терминах модели Браун и Левинсона, здесь побудительный речевой акт (2) также реализован по стратегии позитивной вежливости, к которой относятся форма совместного действия и диминутивные суффиксы (в данном случае делающие речь менее формальной).

Павел опять никак не реагирует словами на побуждение. Потом он, убравшись, уходит (можно предположить, что выливать воду), а Мария ищет его глазами. Затем, через 16 минут после первой попытки Марии побудить Павла заняться новой тарелкой, он приступает к этому действию:

\section{Фрагмент 4}

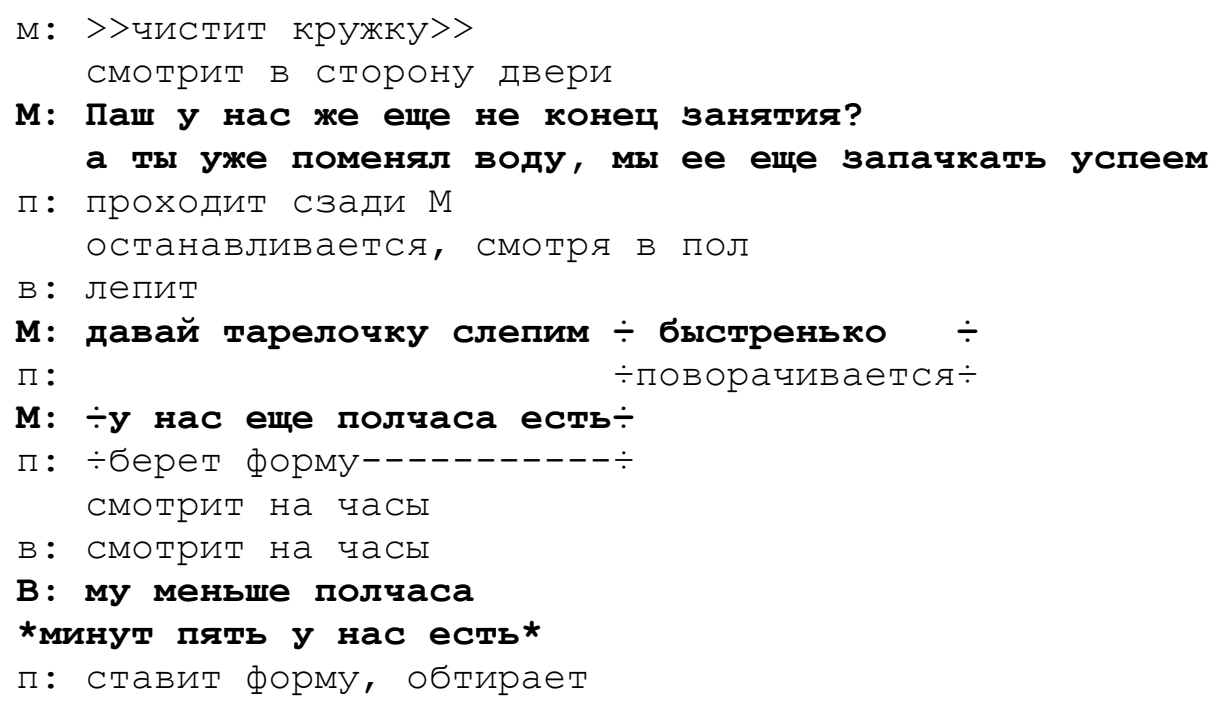

В данном фрагменте побудительный речевой акт (8) оформлен аналогично варианту из предыдущего фрагмента (с позитивной вежливостью, по Браун и Левинсону). За побудительной репликой сразу следует действие: Павел поворачивается и берет форму для лепки тарелки. Однако к такому результату привела не одна фраза Марии, а в совокупности все попытки, но главное, общий ход взаимодействия: разговор о животных закончен, уборка завершена, и поэтапно, в своем режиме, Павел уже готовился к лепке.

Таким образом, переключение к рабочей деятельности может стать проблемой для участников. Описанные попытки можно рассматривать как составляющие процесса побуждения, который значительно растянут по времени. Переключение к рабочей деятельности оказывается для Павла многоэтапным процессом. 


\section{6 Выводы}

Переключение между двумя видами деятельности (разговором и ручным трудом) осуществляется по-разному у разных участников: у нейротипичных - более резко, а у аутичного - поэтапно. Два курса деятельности соотносятся для аутичного сотрудника таким образом, что он говорит только о животных, но выполняет действия, связанные с работой. Ни в одном из случаев он не отвечает на реплики, касающиеся рабочей деятельности, словами. В целом, разговор о животных занимает его в большей степени.

На основании анализа фрагментов можно выделить следующие закономерности относительно эффективности побуждения аутичного участника к действию. Успешнее оказывается побуждение, если оно сопровождается невербальными действиями, требующими ответных: напр., дать палочки. Кроме того, важен общий ход взаимодействия: побуждение результативнее, если происходит в момент, когда разговор на нерабочие темы подошел к завершению или в случае естественной паузы в нем. Анализ, пусть и такого ограниченного материала, с точки зрения модели вежливости, показывает, что реакция аутичного участника на побудительное действие не зависит от языковой формы речевого акта (в том числе от средств вежливости).

Отсутствие какого бы то ни было ответа на побуждение - инициирующие реплики первой пары - даже в тех случаях, когда желаемое действие не выполняется, нарушает связность взаимодействия и отличается от «типичного» сценария (по которому в случае невыполнения действия, формулируется отказ или предлагаются другие варианты). Можно предложить не трактовать отсутствие ответа на побудительный речевой акт как его игнорирование и связать с особенностями переключения между разными видами деятельности.

На успешность переключения к рабочей деятельности можно взглянуть с учетом более широкого контекста и задач инклюзивного пространства, одна из которых - создание условий для непринужденного общения. В этом смысле переключение к рабочей деятельности можно назвать успешным, если оно позволяет поддерживать текущую беседу, не нарушая общего хода взаимодействия и гармонично встраиваясь в него.

Итак, мультимодальный анализ взаимодействия демонстрирует различия в том, как происходит переключение между видами деятельности у аутичных и нейротипичных участников. Подход, при котором принципы нейротипичного поведения не принимаются за единственно возможную норму, вносит коррективы в моделирование человеческой коммуникации. Результаты подобных исследований могут быть использованы для компьютерного моделирования нейроразнообразного взаимодействия.

\section{References}

[1] Baron-Cohen Simon, Leslie Alan. M., Frith Uta. Does the autistic child have a "theory of mind"? // Cognition. 21. 1985. - P. 37-46.

[2] Brown Penelope, Levinson Stephen. Politeness: Some Universals in Language Usage. — Cambridge: Cambridge University Press, 1987. 358 p.

[3] Cummings Louise. Pragmatic disorders // Cognitive pragmatics [Handbook of Pragmatics, Vol. 4], ed. by H.J. Schmid. 2012. - P. 291-315.

[4] Dobbinson Sushie, Perkins Michael R., Boucher Jill. The interactional significance of formulas in autistic language // Clinical Linguistics \& Phonetics. 17(4-5). 2003. - P. 299-307.

[5] Drew Paul, Couper-Kuhlen Elizabeth. Requesting - from speech act to recruitment // Requesting in Social Interaction, Studies in Language and Social Interaction / ed. by P. Drew, E. Couper-Kuhlen. Amsterdam / Philadelphia: John Benjamins, 2014. - P. 1-34.

[6] Haddington Pentti, Keisanen Tiina, Mondada Lorenza, Nevile Maurice. Towards multiactivity as a social and interactional phenomenon // Multiactivity in social interaction: Beyond multitasking, ed. by Haddington P., Keisanen T., Mondada L., Nevile M. John Benjamins Publishing Company. 2014. — P. 3-32.

[7] Kamunen Antti, Haddington Pentti. From monitoring to co-monitoring: Projecting and prompting activity transitions at the workplace // Gespächsforschung 21. 2020. — P. 82-122.

[8] Local John, Wootton Anthony J. Interactional and Phonetic Aspects of Immediate Echolalia in Autism: A Case Study // Clinical Linguistics and Phonetics. 9. 1995. - P. 155-194.

[9] Maynard Douglas. W., Turowetz Jason. Sequence and Consequence: Transposing Responsive Actions into Provocations in Forensic and Clinical Encounters Involving Youths with Autism // Atypical Interaction. Ed. by Wilkinson R., Rae J., Rasmussen G. 2020. — P. 39-63. 
[10] Medvedovskaja T.A., Lebedeva E.I. (2011) How we understand behaviour of other people, or "theory of mind" [Kak my ponimaem povedenie drugih ljudej, ili «model' psihicheskogo»] // Autism and developmental disorders [Autizm i narushenija razvitija], 2 (33), pp. 22-34.

[11] Milton Damian. On the ontological status of autism: the double empathy problem // Disability and Society. 27 (6). 2012. - P. 883-887.

[12] Mondada Lorenza. Conventions for multimodal transcription. 2018. https://www.lorenzamondada.net/multimodal-transcription.

[13] Ochs Elinor, Kremer-Sadlik Tamar, Sirota Karen G., Solomon Olga. Autism and the social world: an anthropological perspective // Discourse Studies. 6. 2004. - P. 147-183.

[14] Ogiermann Eva. Object requests: Rights and obligations surrounding object possession and object transfer // Journal of Pragmatics. 82. 2015. - P. 1-4.

[15] Rae John P., Ramey Monica. Making and Taking Opportunities for Co-participation in an Interaction Between a Boy with Autism Spectrum Disorder and His Father // Atypical Interaction. Ed. by Wilkinson R., Rae J., Rasmussen G. 2020. - P. 65-92.

[16] Rossi Giovanni. The Request System in Italian Interaction. Ph.D Thesis. Radboud University, Nijmegen, 2015. xvii, 287 p.

[17] Rudneva Ekaterina. How Russians pre-request and seek assistance: a study of interaction in two communities of practice // Russian Linguistics. 43 (2). 2019. — P. 127-142.

[18] Williams Gemma. Talking together at the edge of meaning: Mutual (mis)understanding between autistic and non-autistic speakers. PhD thesis. University of Brighton. 2020.

\section{Приложение А. Список обозначений, используемых в транскрипции}

\begin{tabular}{|l|l|l|}
\hline, & Завершенность синтагмы и небольшая пауза. \\
\hline$(0.3)$ & Пауза более 0,1 секунды с указанием длины паузы. \\
\hline та:к & Растягивание звука. \\
\hline ВОду & Увеличение громкости. \\
\hline$?$ & Интонация вопроса. \\
\hline $\begin{array}{l}\text { М: [так Паш] } \\
\text { П: [ну и что ]тоже }\end{array}$ & Одновременное говорение. \\
\hline *минут пять у нас есть* & Слова произносятся тише по сравнению с предшествующими. \\
\hline$(? ?)$ & Неразборчивая речь. \\
\hline
\end{tabular}

